\title{
Spectrometric analysis of heavy metal in Parthenium hysterophorus medicinal plant collected from district Karak and Peshawar
}

\author{
Faheem Tariq ${ }^{1 *}$, Muhammad Asim ${ }^{1}$, Izhar Ahmad ${ }^{1}$, Sher Wali ${ }^{1}$, \\ Khushnood Ur Rehman ${ }^{1}$ and Hafsa Bibi ${ }^{2}$ \\ 1. Department of Botany, Islamia College Peshawar-Pakistan \\ 2. Department of Botany, Qurtaba University of Science and Technology, Peshawar-Pakistan \\ *Corresponding author's email: imfaheem93@gmail.com
}

Citation

Faheem Tariq, Muhammad Asim, Izhar Ahmad, Sher Wali, Khushnood Ur Rehman and Hafsa Bibi. Spectrometric analysis of heavy metal in Parthenium hysterophorus medicinal plant collected from district Karak and Peshawar. Pure and Applied Biology. Vol. 9, Issue 2, pp1376-1384. http://dx.doi.org/10.19045/bspab.2020.90144

\begin{tabular}{llll}
\hline \hline Received: 15/11/2019 & Revised: 25/01/2020 & Accepted: 20/02/2020 & Online First: 03/03/2020 \\
\hline
\end{tabular}

\section{Abstract}

The contamination by heavy metals in plants is one of the major problems faced by the entire planet and it requires attention because when heavy metals exceeds from normal ranges, it becomes enormously susceptible to the plant. It was therefore a matter of great attention to carry out a study to calculate approximate levels of heavy metals in plants of district Karak and Peshawar. In the present study, a heavy metal such as $\mathrm{Cd}, \mathrm{Cu}, \mathrm{Fe}$, and $\mathrm{Pb}$ was investigated in a medicinally important plant, Parthenium hysterophorus by using atomic absorption spectrophotometer. The plant samples were collected from different locations of Karak and Peshawar, Khyber Pakhtunkhwa, Pakistan. The stem, leaves and underground parts were found to contain all heavy metal except Cd. Cu was ranging from 17.25 to $18.69 \mathrm{mg} / \mathrm{kg}$ in Karak and 17.35 to $19.78 \mathrm{mg} / \mathrm{kg}$ in Peshawar, i.e. above the permissible limit set by WHO in all the plant samples. Fe was from 3.42 to $14.33 \mathrm{mg} / \mathrm{kg}$ in Karak and 4.17 to $15.12 \mathrm{mg} / \mathrm{Kg}$ in Peshawar, which is below the permissible limit set by WHO. Pb was 4.32 to $6.45 \mathrm{mg} / \mathrm{kg}$ in Karak and 1.47 to $7.82 \mathrm{mg} / \mathrm{Kg}$ in Peshawar that is above the permissible limit in the roadside plants.

Keywords: Karak; National highway (NHA); Peshawar; Parthenium hysterophorus;

Spectrometric analysis

\section{Introduction}

Invasive plant species often produces a severe and irreversible impact on agriculture, natural resources, environment, an economy. Invasive plant and animal species not only affect our environment and economy but also endangered native plants and animals, along with other aspects of biodiversity. Hundreds of species extinctions, all over the world are caused by the invasive species, which can invade in almost every type of local flora and fauna [1]. Parthenium hysterophorus ( $P$. hysterophorus) has both direct and indirect effects on domestic's animal production significantly and affect animal health, milk, meat, quantity and quality, and grazing land. 
It also affects the marketing of pasture seeds and grains [2]. Some serious human health problems were reported in Pakistan as well as other Asia countries from P. hysterophorus more than two decades ago. $P$. hysterophorus cause allergy, some of the initial symptoms of allergy caused by its contacts are itchiness, blisters on the eyelids, neck, face swelling and redness in later extended to the knee, elbow, and wrist. Allelopathic properties of $P$. hysterophorus inhibit the germination of natural vegetation which is not evolutionary adapted to the characteristics that $P$. hysterophorus has developed so they can't survive in competition with it. That's why the population of natural vegetation is gradually decreased in the areas occupied via $P$. hysterophorus.

$P$. hysterophorus normally grows in agricultural, rural and urban areas, forestlands, flood plains, overgrazed pastures and along the roadside and railway tracks. The exchange of machinery, vehicle movement and livestock are main sources of spreading $P$. hysterophorus. It can be controlled by washing the vehicles then allow into non-infected areas. The livestock dispersion can be controlled by restricting livestock in a small cabin and allow the seeds to fall from their bodies and then permit them into areas free of $P$. hysterophorus. Purchasing farm species also need attention to be examined for contamination by $P$. hysterophorus seeds. Substitution of $P$. hysterophorus via other plants can be accomplished by establishing Cassia sericea and $C$. sparsiflorus.

$P$. hysterophorus has been reported as the main cause of total changes in the Australian environment and native flora, due to Parthenium as invasive species. In the Parthenium hysterophorus subjected areas are scant or sometimes no other vegetation can be seen because of its allelopathic effect [3]. An invasion of weeds substitutes the inherent species in Asian countries, which is a serious risk to biodiversity. Akter and Zuberi [4] conducted a survey in Bangladesh on IAS (Invasive Alien Species) and their influence on the farmstead, the roadside, railway route, and fallow land. $P$. hysterophorus confirmed the ability germination of other plant and settle into the fresh ecological unit by sinking the number of plants in a new environment [4]. The possession of secondary metabolites and a high rate of reproduction give the $P$. hysterophorus the robust position of invasiveness.

The present study was conducted to find out, whether P. hysterophorusis is suitable for the controlling environmental pollutants such as heavy metal and for medicinal purposes. Findings of this study would be useful for understanding, how the heavy metal content in roadside plants is influenced by traffic activities and helpful in making policies for avoiding harmful heavy metal contaminants in medicinal plants in areas of the district Karak and Peshawar.

\section{Materials and methods Sampling}

The underground and stem leave parts of the plant were collected from two different locations at Tarkhakoi Karak, and University Road of district Peshawar, Khyber Pakhtunkhwa, Pakistan, shown in (Fig. 1). First one was collected very close to the National Highway Authority (NHA) and second on the distance of about 1 Kilometer from NHA Karak. Similarly, the plants were first collected from University road side and then second collection was done, one $\mathrm{Km}$ away from University road of Peshawar. The underground parts of the plant were washed with tap water and aerial parts were cleaned to get dust-free samples. These were brought to the laboratory and again washed with distilled water. Aerial and underground parts were kept in an oven and dried separately at about $80-90{ }^{\circ} \mathrm{C}$. The aerial and underground parts were crushed via physical means and 
made a powder of it. Powder of each part was kept in an oven in a china dish at $80-90{ }^{\circ} \mathrm{C}$ to get dried and moisture-free samples.

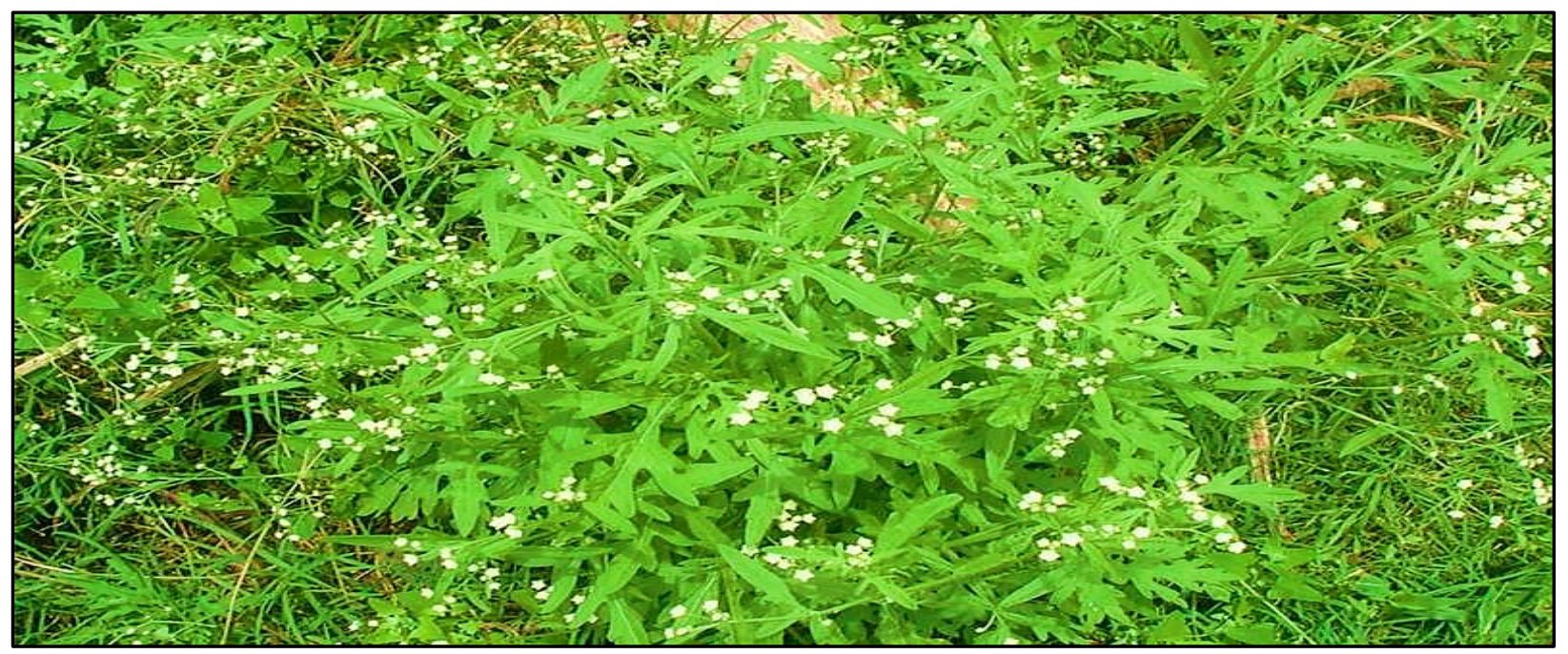

Figure 1. Showing Parthenium hysterophorus plant collected from district Karak

\section{Reagents}

Nitric acid $\left(\mathrm{HNO}_{3}\right)$ and hydrogen peroxide $\left(\mathrm{H}_{2} \mathrm{O}_{2}\right)$ were used. For the dilution of different solutions, distil water was used. At the start and end of a process, all the apparatus was carefully washed and put in an oven at 60 to $70{ }^{\circ} \mathrm{C}$ for dryness.

\section{Dry Ash's}

Dry ash through the furnace, 2 to $3 \mathrm{~g}$ sample place in ceramic crucible and heated in the muffle furnace shown in (Fig.2a, b). The furnace temperature was adjusted to 460 and $550{ }^{\circ} \mathrm{C}$ and became ashes after $4 \mathrm{~h}$. Liquefy in $7 \mathrm{~mL}$ of $\mathrm{HNO}_{3}$ and the solution was heat. Then leached ash with $3 \mathrm{M} \mathrm{HCL}$ and then dilute to $25.0 \mathrm{~g}$ with distilled water and stock for analysis [5].
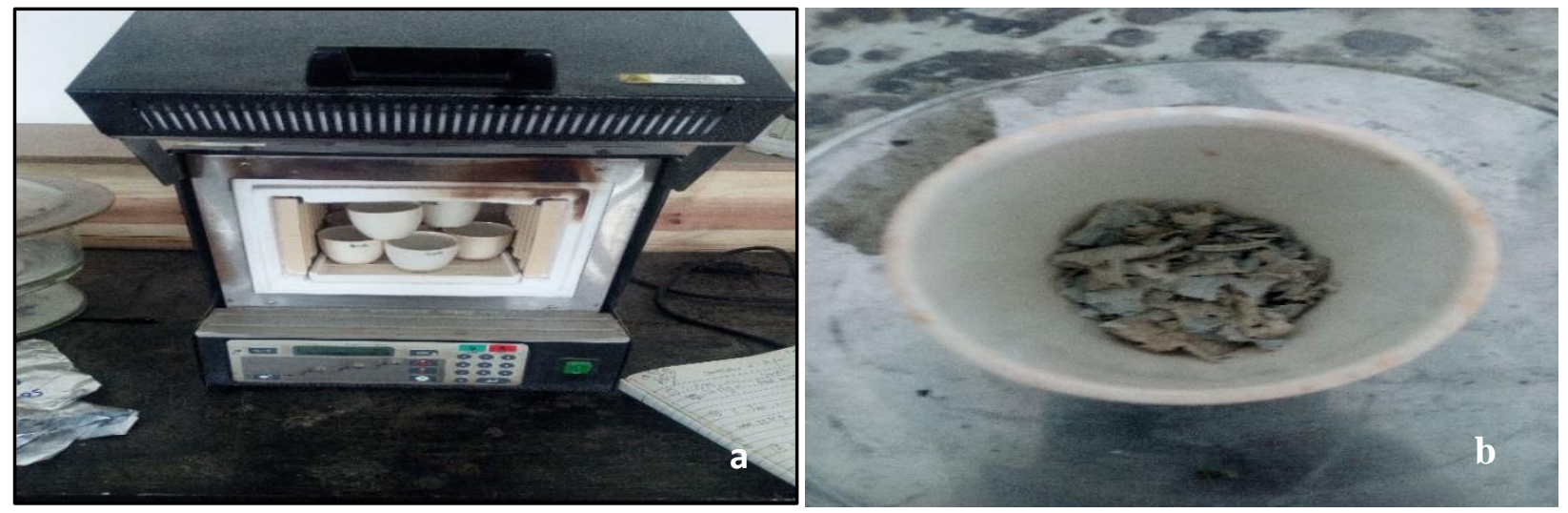

Figure 2. The aerial part and roots were burn to ashes (a) Furnace (VULCAN TM 3-130) (b) Crucible with ash content 


\section{Wet digestion and determination}

A sample of $1 \mathrm{~g}$ was taken in $250 \mathrm{~mL}$ conical flask. $25 \mathrm{ml}$ concentrated nitric acid $\left(\mathrm{HNO}_{3}\right)$ and 2.0-milliliter hydrogen peroxide $\left(\mathrm{H}_{2} \mathrm{O}_{2}\right)$ was added as a catalyst and placed in a digestion chamber on the electric heating plate. Then increase the temperature gradually from room temperature up to 160 to $170{ }^{\circ} \mathrm{C}$. The digestion was completed in about 14 to $16 \mathrm{~h}$, as indicated the appearance of approximately 5.0-milliliter white grey solution. The digested solution was left to become cool; the content of the flask was poured to a $50 \mathrm{ml}$ graduated tube. Add concentrated nitric acid and dilute up to 25.0 $\mathrm{g}$ with distil water to increase the volume up to 7.0 milliliter, the process was repeated three times for each of the four samples and stored for further process. The concentration of cadmium, iron, and lead were determined in the solution by Atomic Absorption Spectroscopy (Model: Perkin Elmer 400, chemistry department, KUST), as shown in (Fig. 3a, b). For each of the sample, the analysis was carried out three times, taking an average of these results, the data were plotted in milligram per kilogram $(\mathrm{mg} / \mathrm{Kg})$ $[6,7]$.
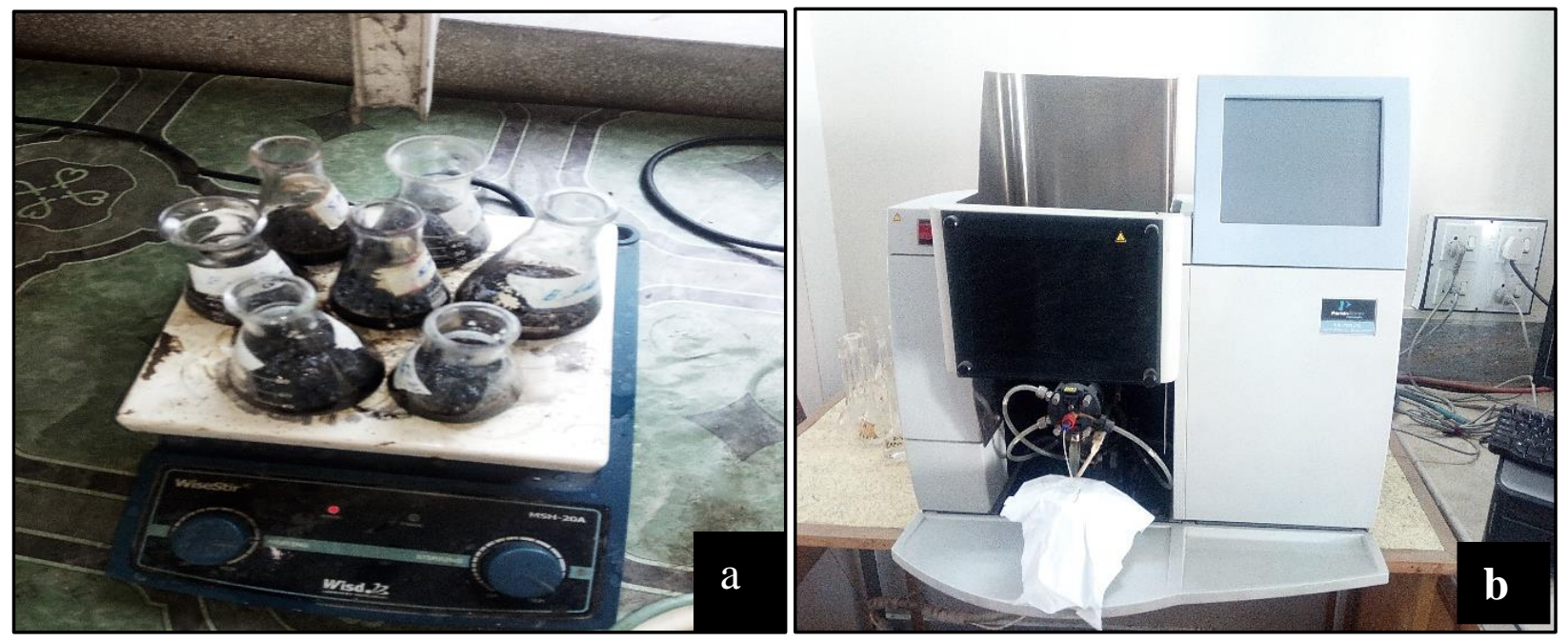

Figure 3. The aerial part and roots were used to carry out elemental analysis as shown in figure (a) Acid Digestion (b) Atomic absorption spectrometer (Perkin Elner instruments, AAnalyst 200)

\section{Results and discussion \\ Lead $(\mathbf{P b})$}

WHO (World Health Organization) recommended the permissible limits of lead in plants is 2 milligrams per kilogram $(\mathrm{mg} / \mathrm{Kg})$. Lead in the environment is considered as contaminated in the environment and ingestion or inhalation of lead are poisonous to human health. It can cause brain disorder by damaging the neuron cell. The results show that aerial and underground parts of $P$. hysterophorus lead concentration were below the threshold value away from the road side, while in the roadside plants both aerial and underground parts have a concentration of lead above the threshold value as shown in (Table $1 \& 2$ ).

\section{Iron $(\mathbf{F e})$}

It is present on earth crust and the suggested value set by WHO is 20 milligram per Kilogram in plants. The result of the sample analysis showed that iron concentration was below the permissible limits as shown in (Table $1 \& 2$ ).

Copper $(\mathrm{Cu})$ 
The acceptable value of copper is 10 milligram per kilogram mentioned by WHO. The analysis of the entire sample showed that copper concentration recorded was above the acceptable value. The main sources of copper in a biosphere are chemical industries, volcanic eruptions, and ore treating services, copper smelter and anthropogenic activities.

Cadmium (Cd)

As evident from (Table $1 \& 2$ ). The results clearly indicate that cadmium was not detected in all the aerial as well as underground parts of plant samples.

Table 2. Concentration of heavy metal $(\mathrm{mg} / \mathrm{kg})$ in $P$. hysterophorus aerial and underground parts, standard deviation (S.D) and not detected (N.D), Collected from district Peshawar

\begin{tabular}{|c|c|c|c|c|}
\hline Sample & $\begin{array}{c}\text { Average } \\
\text { concentration } \\
\text { of Pb } \pm \text { S. D }\end{array}$ & $\begin{array}{c}\text { Average } \\
\text { concentration of } \\
\text { Fe } \pm \text { S. D }\end{array}$ & $\begin{array}{c}\text { Average } \\
\text { concentration of } \\
\text { Cu } \pm \text { S. D }\end{array}$ & $\begin{array}{c}\text { Average } \\
\text { concentration } \\
\text { of Cd } \pm \text { S. D }\end{array}$ \\
\hline $\begin{array}{c}\text { University road side aerial } \\
\text { parts }\end{array}$ & $7.82 \pm 0.12$ & $4.53 \pm 0.27$ & $19.87 \pm 0.12$ & N. D \\
\hline $\begin{array}{c}\text { University road, } \\
\text { underground parts }\end{array}$ & $4.39 \pm 0.19$ & $4.17 \pm 0.17$ & $18.91 \pm 0.21$ & N. D \\
\hline $\begin{array}{c}\text { Away from university road } \\
\text { aerial parts }\end{array}$ & $1.96 \pm 0.19$ & $15.12 \pm 0.17$ & $19.78 \pm 0.16$ & N. D \\
\hline $\begin{array}{c}\text { Away from university road } \\
\text { underground parts }\end{array}$ & $1.47 \pm 0.2$ & $6.44 \pm 0.12$ & $17.35 \pm 0.16$ & N. D \\
\hline
\end{tabular}

Table 1. The concentration of heavy metal $(\mathrm{mg} / \mathrm{kg})$ in $P$. hysterophorus aerial and underground parts, standard deviation (S.D) and not detected (N.D)

\begin{tabular}{|c|c|c|c|c|}
\hline Sample & $\begin{array}{c}\text { Average } \\
\text { concentration } \\
\text { of } \mathbf{P b} \pm \mathbf{S . ~ D}\end{array}$ & $\begin{array}{c}\text { Average } \\
\text { concentration of } \\
\mathbf{F e} \pm \mathbf{S . ~ D}\end{array}$ & $\begin{array}{c}\text { Average } \\
\text { concentration of } \\
\mathbf{C u} \pm \mathbf{S . ~ D}\end{array}$ & $\begin{array}{c}\text { Average } \\
\text { concentration of } \\
\mathbf{C d} \pm \mathbf{S} \text {. D }\end{array}$ \\
\hline NHA side aerial parts & $6.45 \pm 0.29$ & $3.42 \pm 0.21$ & $17.72 \pm 0.15$ & N. D \\
\hline $\begin{array}{c}\text { NHA side, } \\
\text { underground parts }\end{array}$ & $4.32 \pm 0.24$ & $4.12 \pm 0.1$ & $17.19 \pm 0.32$ & N. D \\
\hline $\begin{array}{c}\text { NHA-Distance aerial } \\
\text { parts }\end{array}$ & $1.82 \pm 1.21$ & $14.33 \pm 0.13$ & $18.69 \pm 0.17$ & N. D \\
\hline $\begin{array}{c}\text { NHA-Distance } \\
\text { underground parts }\end{array}$ & $1.45 \pm 0.36$ & $6.47 \pm 0.87$ & $17.25 \pm 0.24$ & N. D \\
\hline
\end{tabular}

The accumulation of heavy metals in medicinal plants and in soil, in which they grow, require the comparison between the metal absorption estimated and reference value reported in the literature or those predictable by the regulatory authorities like WHO. In the present study, heavy metals like $\mathrm{Cd}, \mathrm{Cu}, \mathrm{Fe}$, and $\mathrm{Pb}$ were calculated in a medicinal plant, $P$. hysterophorus as shown in (Fig. 4a \& b, 5a \& b, 6a \& b, 7a \& b).
The results showed a higher concentration of lead in the $P$. hysterophorus plant. The order of lead concentration in different parts of plants was, roadside aerial parts $>$ the roadside, underground parts $>$ aerial parts present at distance from road $>$ underground present at road distance parts. The results showed that a plant collected from the different location absorb the different quantity of lead. These results showed 
accordance with the results of Naser et al., 2012 [8]. A roadside aerial plant part were sensitive and road distance underground parts was less sensitive. The high concentration of lead in the aerial parts can be judiciously clarified by the high concentration of lead in the roadside environment due to vehicular heavy metal production events. Mechanism of engine and fuel oil consumption, which usually contain a high amount of lead are mainly responsible for lead emission. Hence, a high amount of lead in the roadside aerial plant parts primarily linked to road traffic pollution. Beside vehicle emission, some other aspects like chemical industries, agricultural fertilizers, herbicides, insecticides, and anthropogenic activities also influence the concentration of lead. The lead concentration in the underground parts of medicinal plants is relatively low because these parts are not directly concerned to the polluted environment. Whereas, lead is usually conveyed over and done with air confession. A similar type of results was obtained, in which results indicate that the concentration of lead in a plant is inversely proportional to the distance of a plant from the road [9]. That's why the observed value of lead concentration in aerial as well as underground parts of plants present at the road distance was below the permissible limit set by WHO [10].

Iron concentration in all the plant samples was recorded below the permissible limit.
The decreasing concentration of iron in a plant from all spots was, the road distance aerial parts > road distance underground parts $>$ roadside underground parts $>$ roadside aerial parts. As an iron one of the essential elements required for plant growth. Traffic activities are the main cause of polluted environment which has occupied a high concentration of heavy metal contaminants like $\mathrm{Pb}$ and $\mathrm{Cr}$ etc. Low Fe concentration in the roadside aerial parts may be due to the polluted environment which can directly affect the concentration of $\mathrm{Fe}$ in plants.

Among the various metal studied, $\mathrm{Cu}$ was found in a high concentration in the road distance aerial parts. This may be due to the pesticides and fertilizers which are used for increasing an agricultural product and other anthropogenic activities. The concentration of $\mathrm{Cu}$ in the roadside plants may be due to the polluted environment. The results indicate that the concentration of copper decrease as the distance of plants from the increase. The decreasing concentration order of copper in $P$. hysterophorus is, road distance aerial parts $>$ road distance underground parts $>$ the roadside aerial parts $>$ roadside underground parts.

Unexpectedly, in all the collected plant samples, cadmium was not detected. The only possible reason to explain this is, there is no or less contamination of cadmium in the soil and atmosphere. 

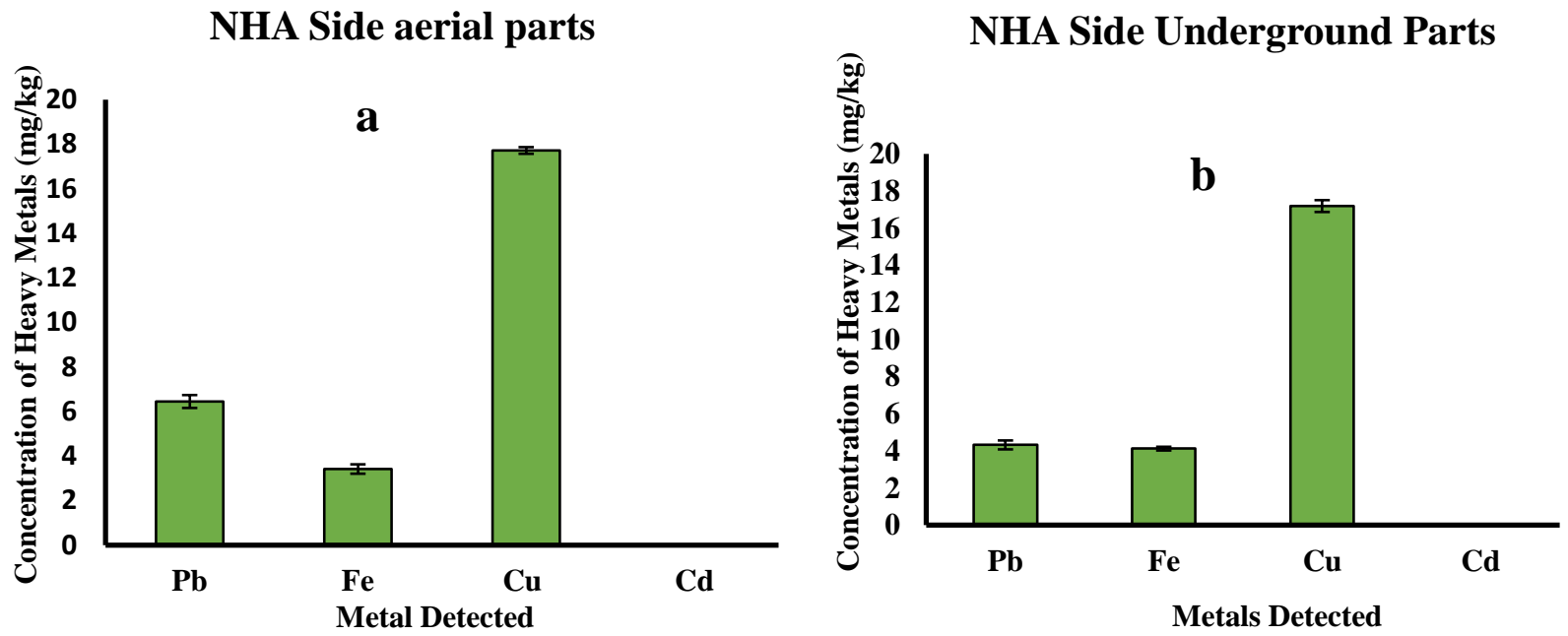

Figure 4. Concentrations of Heavy metals in (a) aerial parts of plants at NHA side (b) underground parts of plants at NHA side.

NHA Distance aerial parts



NHA Distance Underground Parts

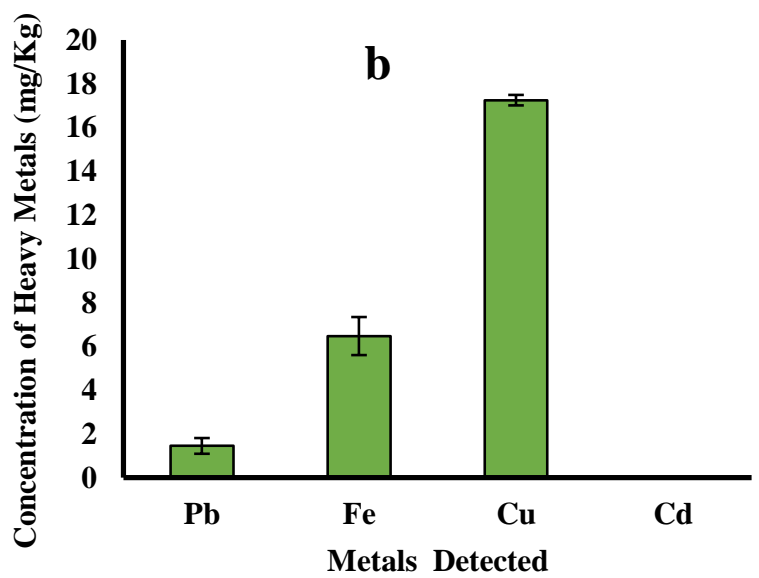

Figure 5. Concentrations of Heavy metals in (a) aerial parts of plants at NHA Distance side (b) underground parts of plants at NHA distance side 



Figure 6. Concentrations of Heavy metals in (a) aerial parts of plants at University roadside of Peshawar (b) underground parts of plants at University roadside of Peshawar


Figure 7. Concentrations of Heavy metals in (a) aerial parts of plants away from university road of Peshawar (b) underground parts of plants away from University road of Peshawar 


\section{Conclusion and recommendations}

It was concluded that the heavy metal concentration in the road distance and roadside plants in the district Karak and Peshawar. It was calculated that the concentration of $\mathrm{Fe}$ was below the permissible level. $\mathrm{Pb}$ and $\mathrm{Cu}$ concentration were above the permissible level. $\mathrm{Cd}$ was not detected. The high concentration of lead and copper in roadside plants indicate that the roadside environment is extremely polluted. This can be reasonably explained in a term of traffic pollution, due to vehicle emission mechanism. For the future relative studies, it is suggested to do more detailed sampling from the road edge in the first 20, 40, 60 and $80 \mathrm{~m}$ for the scattering design of heavy metals.

\section{Author contribution}

Designed and performed experiment: F Tariq \& M Asim, Carried out research: M Asim \& KU Rahman, Analyzed data: F Tariq, I Ahmad \& S wali, Contribution material/ tools analyzed: I Ahmad, KU Rahman \& H Bibi, Wrote paper: F Tariq \& M Asim.

\section{References}

1. Shabbir A \& Bajwa R (2007). Parthenium invasion in Pakistan-A Threat still unrecognized. Pak $J$ Bot 39(7): 2519-2526.

2. Tudor GD, Ford AL, Armstrong TR \& Bromage EK (1982). Taints in meat from sheep grazing Parthenium hysterophorus. Australian $J$ of Exper Agri and Animal Husband 22(115): 4346.

3. Lakshmi C \& Srinivas C (2007). Parthenium: A wide angle view. Indian J of Dermatol, Venereol and Leprol 73(5): 296-306.
4. Akter A \& Zuberi M (2009). Invasive alien species in Northern Bangladesh: identification, inventory and impacts. Inter J of Biodiver and Conserva 1(5): 129-134.

5. Ellen G \& Loon JV (1990). Determination of cadmium and lead in foods by graphite furnace atomic absorption spectrometry with Zeeman background correction: test with certified reference materials. Food Additives \& Contamin 7(2): 265-273.

6. Prichard E, MacKay GM \& Points J (1996). Trace analysis: a structured approach to obtaining reliable results, Royal Society of Chemistry.

7. Ndung'U, K, Hibdon S \& Flegal AR ( 2004). Determination of lead in vinegar by ICP-MS and GFAAS: evaluation of different sample preparation procedures. Talanta, 64(1): 258-263.

8. Naser HM, Sultana S, Mahmud NU, Gomes R \& Noor S (2012). Heavy metal levels in vegetables with growth stage and plant species variations. Bangladesh $J$ of Agri Res 36(4): 563-574.

9. Beladi M, Kashani A, Habibi D, Paknejad F \& Golshan M (2011). Uptake and effects of lead and copper on three plant species in contaminated soils: role of phytochelatin. African $J$ of Agri Res 6(15): 3483-3492.

10. Nazir R, Khan M, Masab M, Rehman HU, Rauf NU, Shahab S, Ameer N, Sajed M, Ullah M, Rafeeq M \& Shaheen Z (2015). Accumulation of heavy metals $(\mathrm{Ni}, \mathrm{Cu}, \mathrm{Cd}, \mathrm{Cr}, \mathrm{Pb}, \mathrm{Zn}, \mathrm{Fe})$ in the soil, water and plants and analysis of physicochemical parameters of soil and water collected from Tanda Dam kohat. $J$ of Pharma Sci and Res 7(3): 89-97. 